\title{
Particle Emission and Exposure during Nanoparticle Synthesis in Research Laboratories
}

\section{Journal Article}

\section{Author(s):}

Demou, Evangelia; Stark, Wendelin J.; Helllweg, Stefanie

Publication date:

2009-11

\section{Permanent link:}

https://doi.org/10.3929/ethz-b-000016134

\section{Rights / license:}

In Copyright - Non-Commercial Use Permitted

\section{Originally published in:}

The annals of occupational hygiene 53(8), https://doi.org/10.1093/annhyg/mep061 


\title{
Particle Emission and Exposure during Nanoparticle Synthesis in Research Laboratories
}

\author{
EVANGELIA DEMOU ${ }^{1 *}$, WENDELIN J. STARK ${ }^{2}$ and \\ STEFANIE HELLWEG ${ }^{1}$
}

\author{
${ }^{1}$ Institute of Environmental Engineering, Department of Civil, Environmental and Geomatic \\ Engineering, ETH Zurich, CH-8093 Zurich, Switzerland; ${ }^{2}$ Functional Materials Laboratory, \\ Department of Chemical and Bioengineering, ETH Zurich, CH-8093 Zurich, Switzerland
}

Received 13 January 2009; in final form 24 July 2009; published online 24 August 2009

\begin{abstract}
Real-time size, mass and number particle concentrations, and emission rates in university laboratories producing nanoparticles by scalable flame spray pyrolysis are quantified. Measurements were conducted in four laboratories using various technological set-ups and during production of particles of a range of compositions with differing physical-chemical properties, from $\mathrm{NaCl}$ salt, $\mathrm{BiPO}_{4}, \mathrm{CaSO}_{4}, \mathrm{Bi}_{2} \mathrm{O}_{3}$, insoluble $\mathrm{TiO}_{2}, \mathrm{SiO}_{2}$, and $\mathrm{WO}_{3}$ to composites such as $\mathrm{Cu} / \mathrm{ZnO}, \mathrm{Cu} / \mathrm{SiO}_{2}, \mathrm{Cu} / \mathrm{ZrO}_{2}, \mathrm{Ta}_{2} \mathrm{O}_{5} / \mathrm{SiO}_{2}$, and $\mathrm{Pt} / \mathrm{Ba}_{/} \mathrm{Al}_{2} \mathrm{O}_{3}$. Production time ranged from 0.25 to $400 \mathrm{~min}$ and yields from 0.33 to $183 \mathrm{~g}$. Temporal and spatial analyses of the particle concentrations were performed indicating that elevated number concentrations in the workplace can occur. Airborne submicron number concentrations increased from background levels of 2100 up to $106000 \mathrm{~cm}^{-3}$ during production, while the mass concentration ranged from a background of 0.009 to $0.463 \mathrm{mg} \mathrm{m}^{-3}$. Maximum particle number emission rates amounted to $1.17 \times 10^{12} \mathrm{~min}^{-1}$. The size distributions displayed concentration peaks mainly between 110 and $180 \mathrm{~nm}$. However, changes in the operating conditions and the production of certain nanoparticles resulted in concentration peaks in the nanoparticle size range $<100 \mathrm{~nm}$. The effectiveness and limitations of current technology in assessing researchers' exposure to nanoparticles during production are examined, and further measures for workers' protection are proposed.
\end{abstract}

Keywords: emission rate; exposure; nanoparticles; size distribution

\section{INTRODUCTION}

Engineered nanoparticles have resulted in novel products with enhanced characteristics and performance. The immense potential of nanoparticles also creates uncertainty regarding to their effects on humans and the environment (Kandlikar et al., 2007). The inability at present to conduct a risk assessment on the impacts of nanoparticles stems in part from the lack of emission and exposure information. Possible scenarios examining exposure using chamber studies and simulated environments and examining exposures from unintentional ultrafine and engineered nanoparticle release have been presented (Kuhlbusch et al., 2004; Maynard et al., 2004; He et al., 2007). These studies show that particle concentrations can be elevated, such as during production of carbon black

\footnotetext{
*Author to whom correspondence should be addressed. Tel: +41-0-44-63-23-172; fax: +41-0-44-63-31-061; e-mail: evangelia.demou@ifu.baug.ethz.ch
}

(Kuhlbusch et al., 2004). Exposure to nanoparticles is specifically expected in the workplace (Maynard and Pui, 2007). Workers' exposure to submicron particles during industrial production of nanostructured particles can be elevated by more than an order of magnitude over background levels (Demou et al., 2008). Research laboratories, however, are a specific workplace environment where attention is needed (Maynard and Pui, 2007), as development, production, and use of existing and new nanoparticles occur in these. Workers producing and using nanoparticles may be exposed mainly via inhalation and skin contact, with most attention to date focusing on the inhalation pathway (Warheit et al., 2007).

Materials produced in the industrial sector, such as carbon black and titania, previously regarded as harmless due to their bulk form properties, could be considered a hazard in their equivalent nano-form (Kandlikar et al., 2007). The dominant hypothesis on the mode of toxic action of nanoparticles to cells is oxidative stress (Warheit et al., 2007), which is 
directly linked to chemical composition and catalytic activity (Brunner et al., 2006; Limbach et al., 2007). Both the extent and mechanism of cell damage appear different under various nanoparticle exposures (Papageorgiou et al., 2007).

Regulatory standards for airborne particulate matter are currently mass based. However, toxicological findings on the size-related and size-dependent toxicity of nanoparticles have led to suggestions of establishing alternative metrics (Grahame and Schlesinger, 2007; Kandlikar et al., 2007). Size, shape, surface area, composition, and solubility are all parameters required to characterize exposure effects of nanoparticles (Warheit et al., 2007). Based on the current knowledge gaps, researchers suggest that it is not possible at present to select an appropriate metric (Warheit et al., 2007).

Industrial production methods of nanoparticles include mechanical processes, colloidal or liquid phase methods, vapour deposition synthesis, and gas-phase processes (Aitken et al., 2004). Flame technology is widely employed in the powder industry and nanoparticle production (Stark and Pratsinis, 2002). Gas-phase processes are comparatively inexpensive (Osterwalder et al., 2006) and commonly used in the production of large volumes of carbon black, zinc oxide, fumed silica, alumina, nickel, and pigmentary titania (Stark and Pratsinis, 2002). Specifically, the flame spray pyrolysis (FSP) technique examined here is of great importance for its potential to scalably produce an array of sophisticated products such as catalysts, sensors, phosphors, dental and orthopaedic materials, fuel cells, battery materials, and even nutritional supplements (Strobel and Pratsinis, 2007).

The goals of this study were to quantify and characterize exposure and emissions as a basis for initial examination on levels, sources, potentials for improvement, and possibilities and limitations in monitoring. This would enhance knowledge to further develop measures and mitigation policies for lowering exposure to nanoparticles. In the absence of reliable information on the toxic effects of nanoparticles, such work is extremely important from a precautionary principle. The specific aims of the paper were (i) to investigate the potential exposure of researchers to nanoparticles in production laboratories using the FSP technique (Madler et al., 2002a); (ii) to characterize the emitted particles in terms of airborne concentration and size, and (iii) to investigate the influence of production techniques and conditions on the airborne exposure concentration.

\section{METHODS}

\section{Instrumentation}

A Scanning Mobility Particle Sizer (SMPS model 3936 including CPC 3775, TSI Inc.), scanning between 20 and $673 \mathrm{~nm}$, was employed for the size distribution measurements (see supplementary Table S1, available at Annals of Occupational Hygiene online, for instrumental settings). Condensation Particle Counters (CPC 3022A and 3007, TSI Inc.) quantified particle number concentrations (PN) (see supplementary Table S1, available at Annals of Occupational Hygiene online), while the aerosol monitors DustTrak ${ }^{\mathrm{TM}}$ (model 8520, TSI Inc.) and SidePak $^{\mathrm{TM}}$ (model AM510, TSI Inc.) measured PM1 and PM10 mass concentrations, respectively. An impactor with a cut-off of $1.0 \mu \mathrm{m}$ (PM1) was used on the DustTrak ${ }^{\top M}$. While optical mass monitors have been shown to be influenced by the composition, shape, and size distributions of particles and can lead to overestimations in mass concentrations (Jenkins et al., 2004; Thorpe, 2007), their use was reasonable in the present study, as they were only used here to compare the temporal profiles between particle metrics during each production event individually. Thermal anemometric instruments, VelociCalc Plus (model 8386A, TSI Inc.), and two Air Velocity Transducers (model 8450, TSI Inc.) measured microenvironmental conditions. The last two instruments measured air velocity, while the former additionally quantified temperature and relative humidity. All instruments, apart from the SMPS system and the CPC 3022A, were calibrated by the manufacturer. Calibration of the CPC 3775 system by the manufacturer required a correction factor of 1.71 due to low inlet flow (Zerrath, A., TSI Inc.).

\section{Experimental plan}

Four academic laboratories studying nanoparticle production by FSP were monitored. This technique involves the formation of nanoparticles from liquids in a flame, under which the chemical reactions and particle growth occur (Madler et al., 2002a; Heine and Pratsinis, 2005). The primary particles produced can range from a few to several hundred nanometers in diameter and are mainly collected in the form of aggregates and agglomerates of primary nanoparticles (Heine and Pratsinis, 2005). The employed flame-spray reactor was either an open-flame source (Madler et al., 2002b) or fully enclosed in a glove box set-up and described in detail elsewhere (Madler et al., 2002b; Athanassiou et al., 2006). Monitoring was conducted under real-time working conditions.

The reactors were placed in fume-hoods except for one that was enclosed in a specially built ventilated compartment for large $\left(1 \mathrm{~kg} \mathrm{~h}^{-1}\right)$ production rates (Laboratory C; see supplementary Figure S1, available at Annals of Occupational Hygiene online). The fume-hoods were always operating during production. All sampling locations were chosen to capture the spatial distribution of the airborne particles at each point in time (Fig. 1 and see supplementary Figure S1, available at Annals of Occupational 
a.

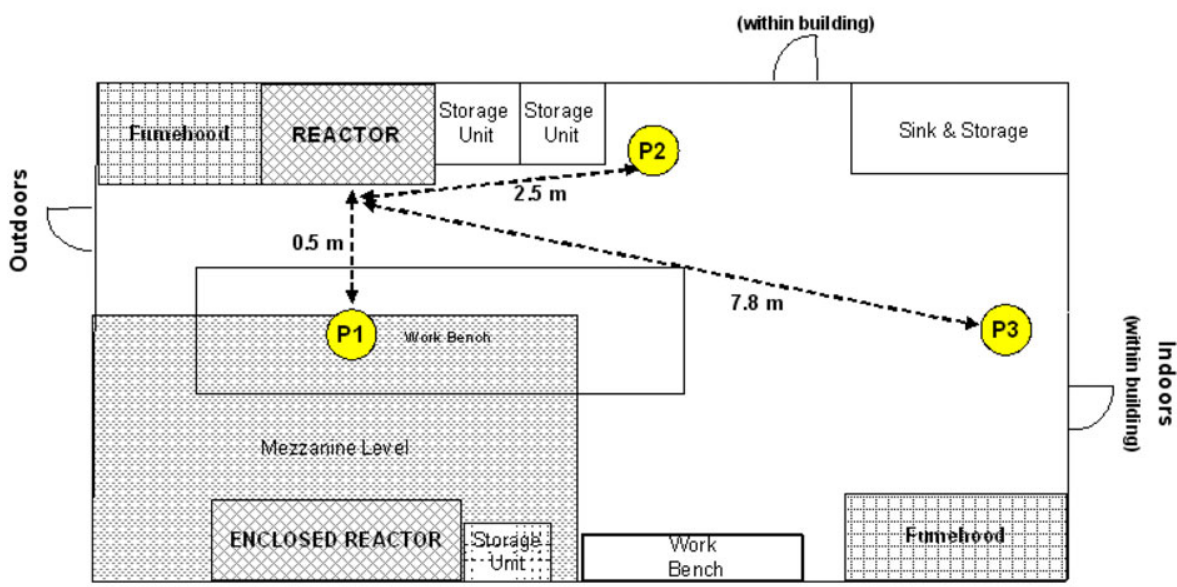

Lab A; Volume; $\mathrm{V}_{\mathrm{A}}=511 \mathrm{~m}^{3}$; Air Exchanges; Exh = 2-10 $\mathrm{h}^{-1}$; Monitoring: P1 - PN1 number and PM1 mass concentration; P2 - size distribution (20 -678 nm) ; and P3 - PN1 number concentration

b.

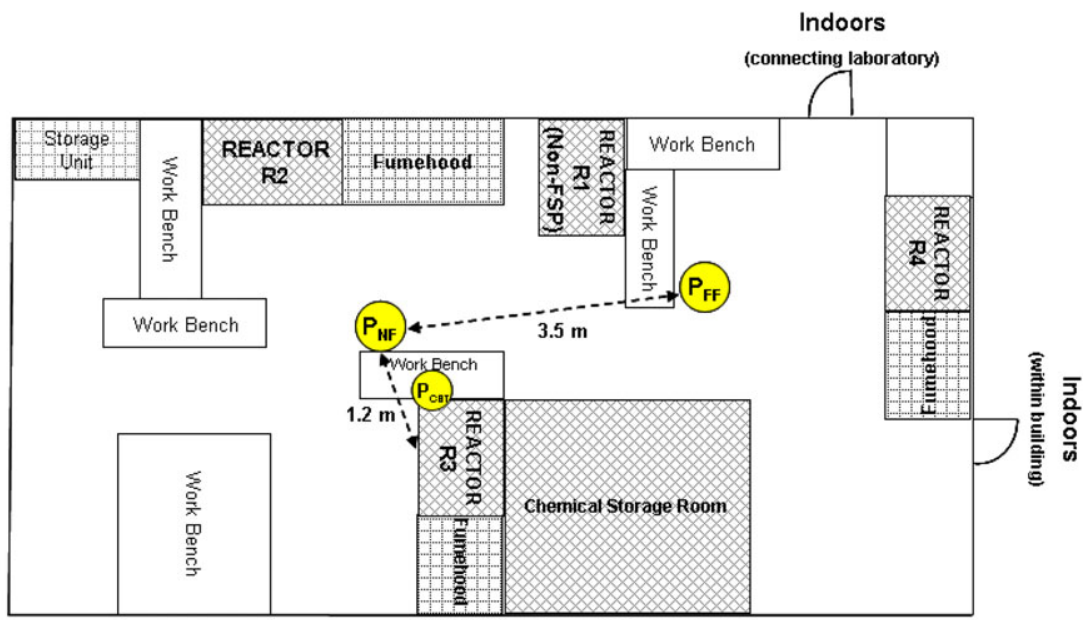

Lab B; Volume; $\mathrm{V}_{\mathrm{B}}=259 \mathrm{~m}^{3}$; Air Exchanges; Exh= 2-10 $\mathrm{h}^{-1}$; Monitoring: $\mathrm{P}_{\mathrm{NF}}$ - PN1 number and PM1 mass concentration; $\mathrm{P}_{\mathrm{FF}}$ - PN1 number concentration and PM10 mass concentration; $\mathrm{P}_{\mathrm{CST}}-\mathrm{PM} 10_{\mathrm{CST}}$ constant mass concentration monitoring.

Fig. 1. Schematic diagram of laboratory set-ups and measurement positions for Laboratory A and Laboratory B (Laboratories C and D are shown in supplementary Figure S1, available at Annals of Occupational Hygiene online).

Hygiene online). In the example of Laboratory A, the measurement positions were selected to represent breathing zone $(\mathrm{P} 1)$ (i.e. within $0.5 \mathrm{~m}$ of the researcher), near-field (P2), and far-field exposure (P3) (Fig. 1). Position P1 was on the working bench and during production the researcher constantly remained there facing both away and towards the inlets. At positions $\mathrm{P} 2$ and P3, other researchers could be conducting secondary work. In Laboratories B, C, and $\mathrm{D}$, only two measurement positions were taken, capturing near-field $\left(\mathrm{P}_{\mathrm{NF}}\right)$ and far-field $\left(\mathrm{P}_{\mathrm{FF}}\right)$ exposures (Fig. 1). Moreover, temporal measurements were performed with all instruments in the same position in Laboratory $\mathrm{B}$, which allowed a comparison of the instrumental readings. All sampling inlets were positioned $\sim 1.2 \mathrm{~m}$ above floor level to represent the breathing zone of a sitting working position.

\section{Production schedule}

In general, one researcher would be carrying out the production while others might be working in the laboratory at the same time. The procedure followed was (i) preparation of system, including feeding of precursor and filter placement (fume-hood open); (ii) flame ignition (fume-hood open); (iii) cleaning, precursor feeding, and production start (fume-hood closed); (iv) production of nanoparticles and collection on filter at the top of the reactor (fumehood closed); (v) production stop, fume-hood door raised approximately halfway for flame extinction 
$(<5 \mathrm{~s})$, and closed again for $1 \mathrm{~min}$ to allow three air exchanges; (vi) fume-hood opening and filter removal; and finally (vii) filter scrapping and particle packing in vials.

\section{Emission rates}

The emission rate of airborne submicron particles during nanoparticle production was estimated in terms of number concentration. Concentrations obtained from the monitoring campaigns in the far-field positions of Laboratory $\mathrm{C}$ and all concentrations from Laboratory $\mathrm{D}$ were used for the estimation of the emission rates. Laboratory $\mathrm{C}$ was chosen because concentrations reach steady state, which facilitates the calculation also for environments with incomplete mixing conditions. The emission rate in Laboratory $\mathrm{C}$ is calculated using equation (1), which refers to the far-field concentration of a Two-Zone model (ten Berge et al., 2000). Laboratory D was chosen due to its low spatial variability in concentration. Background particle number concentrations were subtracted to only account for particles originating from production.

$$
E=C_{\mathrm{F}, \infty} \cdot Q,
$$

where $C_{\mathrm{F}, \infty}$ is the far-field particle number concentration $\left(\mathrm{cm}^{-3}\right)$ at steady state and $Q$ the room ventilation rate $\left(\mathrm{cm}^{3} \mathrm{~min}^{-1}\right)$. Other particle removal processes, such as deposition to surfaces and particle agglomeration were assumed to be insignificant and not considered (see section 'Size distribution').

Laboratory D was the smallest laboratory in volume $\mathrm{V}\left(\mathrm{m}^{3}\right)$ and, thus, the variation in near-field versus far-field particle number concentrations was rather small. Therefore, we could model the entire laboratory as a homogeneously mixed box. The differential equation for the number concentration over time is given by equation (2) (ten Berge et al., 2000).

$$
V \frac{\mathrm{d} C}{d t}=E-Q \times C,
$$

where $C$ is the submicron number concentration $\left(\mathrm{cm}^{-3}\right)$ in the room at time $t ; E$ is the total particle emission (input) rate in terms of particle number $\left(\min ^{-1}\right)$; and $Q$ the room ventilation rate $\left(\mathrm{cm}^{3}\right.$ $\min ^{-1}$ ). The ventilation $Q$ is the product of the room's volume, $V$, and the number of air exchanges, $k\left(\min ^{-1}\right)$. The overall particle removal rate, when estimated from the empirical data of the declining particle concentrations, accounts for all possible particle loss processes, while no differentiation among them is made (He et al., 2007).

Assuming a constant particle emission rate over the production time and integrating equation (1) gives

$$
C=C_{0} e^{-k\left(t-t_{0}\right)}+\frac{E}{k \cdot V}\left[1-\mathrm{e}^{-k\left(t-t_{0}\right)}\right],
$$

where $C_{0}$ is the particle number concentration $\left(\mathrm{cm}^{-3}\right)$ at time $t_{0}$. Solving equation (3) gives the effective particle emission rate [equation (4)].

$$
E=\frac{\left(C-C_{0} e^{-k\left(t-t_{0}\right)}\right)}{1-\mathrm{e}^{-k\left(t-t_{0}\right)}} k \cdot V .
$$

\section{RESULTS}

\section{Production plan}

Monitoring days were chosen at random. Over the 26-day monitoring period, nanoparticle production occurred on 16 days. Of the remaining days, six were background days when no production and almost no activity occurred, while the remaining 4 days had unique conditions, for example, special set-ups, cleaning, and maintenance.

Nanoparticle production in the laboratories covered a wide spectrum of compounds, production schedules and rates, and operating conditions (Fig. 2). A detailed description of the production processes is provided elsewhere (Mädler and Pratsinis, 2002; Grass and Stark, 2005; Loher et al., 2005; Strobel et al., 2006; Osterwalder et al., 2007). Production ranged from highly soluble compounds, such as $\mathrm{NaCl}$, to the common insoluble $\mathrm{TiO}_{2}$ and to highly complex compounds such as a $\mathrm{Pt} / \mathrm{Ba} / \mathrm{Al}_{2} \mathrm{O}_{3}$ catalyst. Production runs lasted between $15 \mathrm{~s}$ and a full working day, with a median of 6 min per run. Total daily median production time was 60 min day ${ }^{-1}$. Nanoparticle production rates ranged from 0.017 to $0.46 \mathrm{~g} \mathrm{~min}^{-1}$ with a median of $0.1 \mathrm{~g} \mathrm{~min}^{-1}$. The product yield collected from the filter over all 59 production runs was between 0.33 and $183.3 \mathrm{~g}$ of powder (Fig. 2).

\section{Number and mass concentrations}

Background particle measurements were conducted on all days (see supplementary Table S2, available at Annals of Occupational Hygiene online). These were conducted on days of no particle production as well as during pre- and post-production activities. Therefore, background measurements encompassed secondary particle sources, such as infiltration from outdoors and activities, such as mechanical processes in setting up and adjusting the reactors for the customized needs of each nanoparticle production event. Average submicron particle number concentrations were $2177 \mathrm{~cm}^{-3}$ [relative standard deviation $(\mathrm{RSD})=46 \%]$ and $2109 \mathrm{~cm}^{-3}(\mathrm{RSD}=46 \%)$ in the near-field and far-field positions, respectively. The background PM1 mass concentration was 0.009 $\mathrm{mg} \mathrm{\textrm {m } ^ { - 3 }}$ and showed a high variability with a RSD of $114 \%$. 


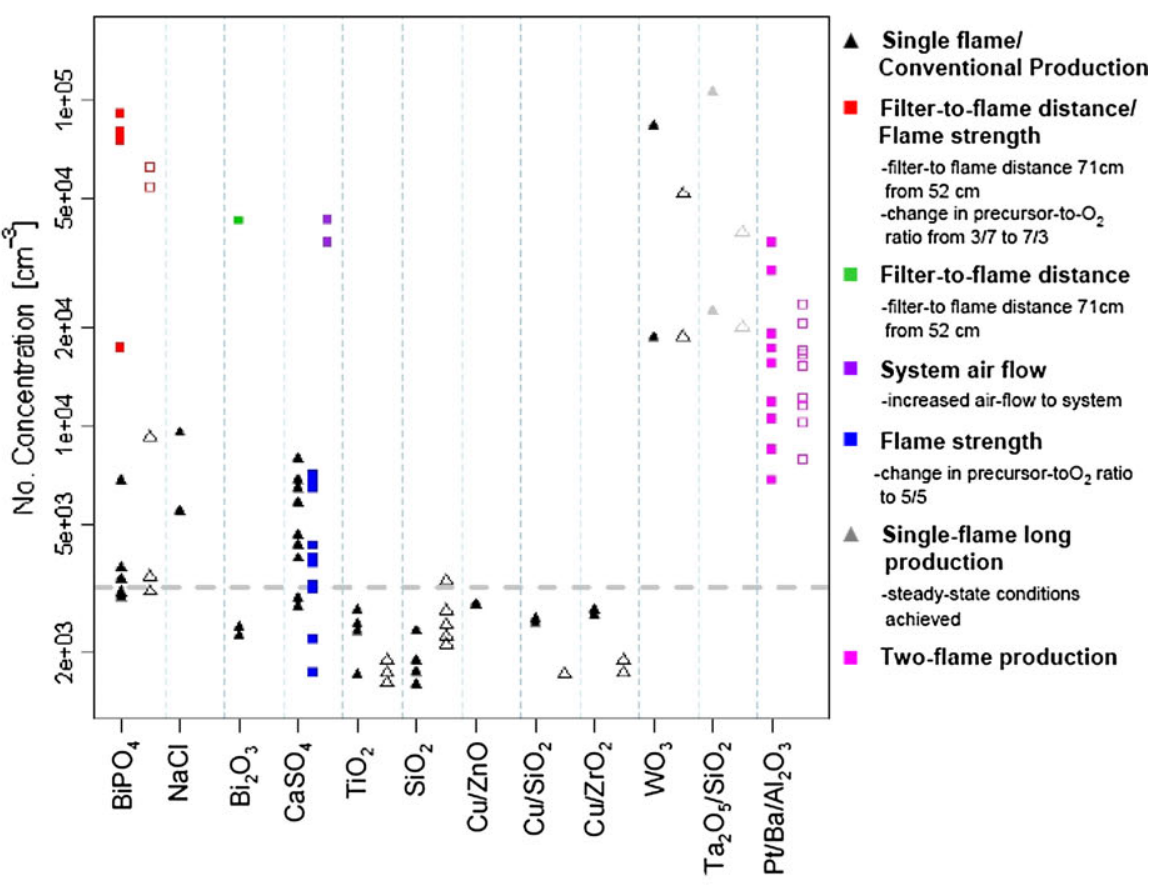

\begin{tabular}{|c|c|c|c|c|c|c|c|c|c|c|}
\hline \multirow[t]{2}{*}{ Lab_Day* } & \multirow[t]{2}{*}{ Particle Type } & \multicolumn{2}{|c|}{$\begin{array}{l}\text { Production } \\
\text { Time }\end{array}$} & \multicolumn{2}{|c|}{ Yield [g] } & \multicolumn{2}{|c|}{$\begin{array}{l}\text { Time Lag of } \\
\text { Peak Conc. }\end{array}$} & \multicolumn{2}{|c|}{$\begin{array}{l}\left.\text { No. Conc. }{ }_{[\mathrm{PEAK}}\right]^{\prime} \\
\left.\text { BG Conc. }{ }_{[\mathrm{AVE}}\right]^{* *}\end{array}$} & \multirow[t]{2}{*}{ Notes } \\
\hline & & $\min$ & $\max$ & $\min$ & $\max$ & $\min$ & $\max$ & $\min$ & $\max$ & \\
\hline A1\&A9 & $\mathrm{BiPO}_{4}$ & 1 & 14 & 0.4 & 3 & 1 & 3 & 1.09 & 42.0 & Product expected size $\sim 40 \mathrm{~nm}$ \\
\hline Al & $\mathrm{NaCl}$ & 1 & 6 & - & - & - & 1 & - & 2.49 & $\begin{array}{l}\text { Product expected size range } \\
60-80 \mathrm{~nm}\end{array}$ \\
\hline A2 & $\mathrm{Bi}_{2} \mathrm{O}_{3}$ & 4 & 7 & - & 2.3 & 1 & 2 & 1.03 & 19.7 & \\
\hline A4-A6 & $\mathrm{CaSO}_{4}$ & 3 & 12 & 0.8 & 0.9 & 1 & 4 & 0.8 & 19.8 & $\begin{array}{l}\text { Product expected size: } 20-50 \\
\mathrm{~nm}\end{array}$ \\
\hline B13-B14 & $\mathrm{TiO}_{2}$ & $\begin{array}{l}0.2 \\
5\end{array}$ & 8 & 0.7 & 0.8 & 2 & 5 & 0.8 & 1.12 & $\begin{array}{l}\text { Production at R2 \& R4 } \\
\text { (smaller reactor) }\end{array}$ \\
\hline $\mathrm{B} 13 \& \mathrm{~B} 20$ & $\mathrm{SiO}_{2}$ & 5 & 19 & - & - & 2 & 3 & 0.73 & 1.07 & Production at R2 \& R4 \\
\hline B14 & $\mathrm{Cu} / \mathrm{ZnO}$ & 25 & 38 & 1.7 & 2.6 & - & 3 & - & 1.3 & Production at R3 \\
\hline B14 & $\mathrm{Cu} / \mathrm{SiO}_{2}$ & 25 & 30 & 1.4 & 1.6 & - & 5 & - & 1.13 & Production at R3 \\
\hline B14 & $\mathrm{Cu} / \mathrm{ZrO}_{2}$ & 10 & 23 & 1.01 & 2.33 & - & 1 & - & 1.19 & Production at R3 \\
\hline B16-B17 & $\mathrm{WO}_{3}$ & 10 & 18 & - & - & - & - & 8.6 & 38.3 & $\begin{array}{l}\text { Cleaning flame ran for 2-3 min } \\
\text { before production. }\end{array}$ \\
\hline $\mathrm{C} 21$ & $\mathrm{Ta}_{2} \mathrm{O}_{5} / \mathrm{SiO}_{2}$ & - & 400 & - & 183.3 & - & 5 & 10.3 & 48.7 & $\begin{array}{l}\text { Product expected size: } \sim 10 \mathrm{~nm} \text {; } \\
\text { mostly non-hard agglomerates }\end{array}$ \\
\hline D22-D23 & $\mathrm{Pt} / \mathrm{Ba} / \mathrm{Al}_{2} \mathrm{O}_{3}$ & - & 20 & - & - & 1 & 4 & 3.12 & 16.83 & 2-flame combination technique \\
\hline
\end{tabular}

Fig. 2. Near-field (filled symbols) and far-field (open symbols) peak number concentrations for all production events. Single-flame and conventional production events are represented by triangles (filled and open). Technological changes in production are represented by squares (filled and open). The technological change of each event is indicated in legend. A description of the production runs is shown in the table below the graph.

Figure 3 displays an example of the number and mass concentration profiles during the production of tungsten trioxide $\left(\mathrm{WO}_{3}\right)$ in Laboratory B. One production event of $\mathrm{WO}_{3}$ occurred during this profile. Production was preceded by cleaning where the flame was only burning xylol for $3 \mathrm{~min}$. This resulted in a sharp increase in number concentration for the duration of the flame-cleaning process (Fig. 3). Production of $\mathrm{WO}_{3}$ nanoparticles lasted for $18 \mathrm{~min}$. During this time, there is a steady increase in the particle number concentration from background levels to 18700 and $18200 \mathrm{~cm}^{-3}$ in the near field and far field, respectively. PM1 mass concentration rises steadily with the start of the production from background levels to a peak concentration of $0.046 \mathrm{mg} \mathrm{m}^{-3}$. While both concentration metrics follow the production pattern, 
a.

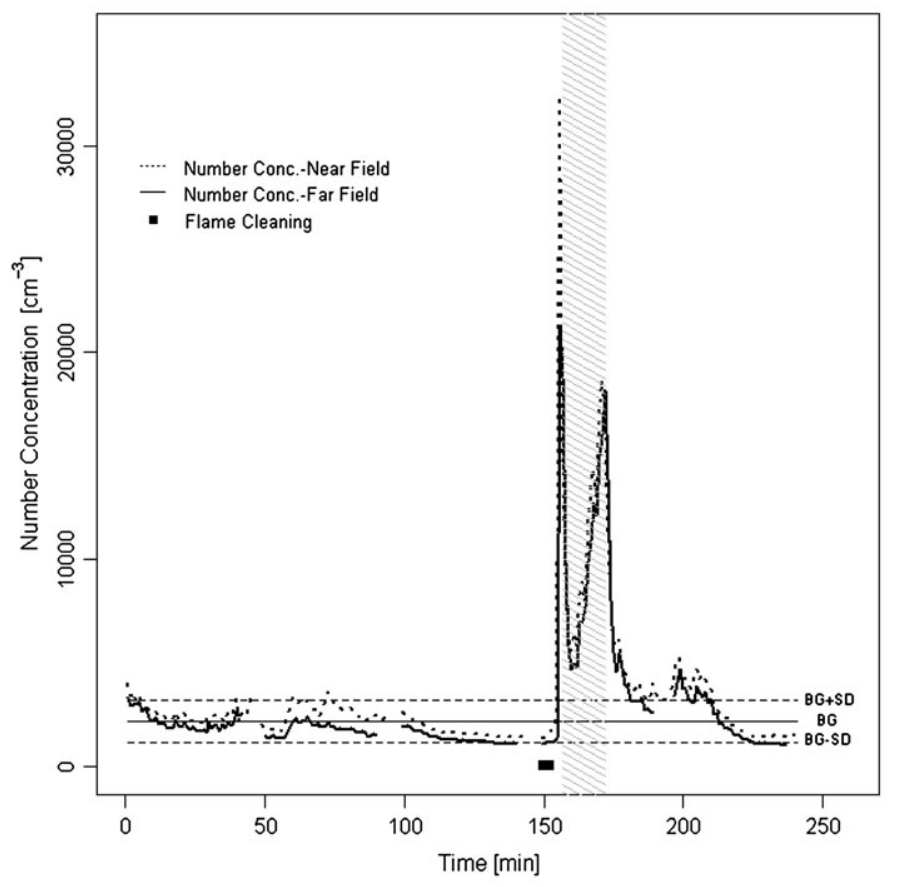

b.

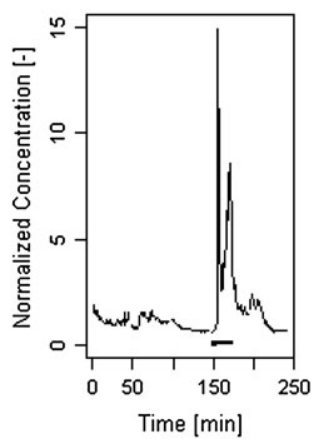

c.

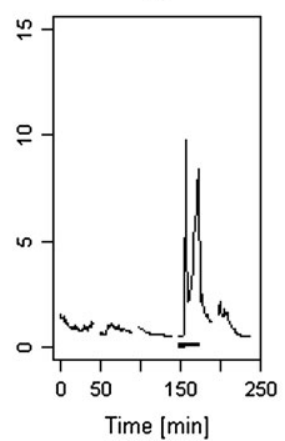

d.

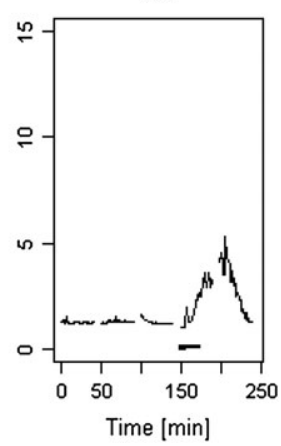

e.

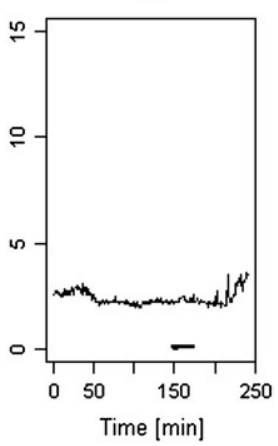

Fig. 3. Particle concentrations during the production (shaded area) of tungsten trioxide $\left(\mathrm{WO}_{3}\right)$ in Laboratory B. (a) Number particle concentrations measured in the near field and far field; (b) $\mathrm{PN} 1_{\mathrm{NF}}$ normalized to background; (c) $\mathrm{PN} 1_{\mathrm{FF}}$ normalized to background; (d) PM1 $1_{\mathrm{NF}}$ normalized to background; (e) PM10 $1_{\mathrm{CST}}$ normalized to background in Laboratory B (position: workbench next to R3).

Fig. 3d shows that the increase in mass concentration occurs slower than the increase in number concentration. Number concentration reaches its peak within a minute after production has ceased, while mass concentration appears to continue to increase for over $30 \mathrm{~min}$ from production end. The number and mass concentrations, normalized to their respective background concentrations (Fig. 3b-d), show that there is no correlation in the rate and magnitude of the increase between the two metrics.

In general, particle number concentration in the near-field and far-field sites showed the same temporal pattern and, in the majority of cases, followed the pattern of production with number concentration increasing with the start of production and peaking between 1 and $5 \mathrm{~min}$ from production end (Fig. 2).
In $45 \%(n=84)$ of the production events, the peak concentration in the breathing and near-field sites was $>3180 \mathrm{~cm}^{-3}$, which is equivalent to the average background plus the standard deviation. In many cases, concentrations were an order of magnitude higher than background concentrations (Fig. 2).

A spatial variability appeared in the airborne particle number concentration, especially during production in Laboratories A-C. The localized source and large room volumes influence this differentiation. On average, the near-field number concentration peak was higher than that of the far field by $32 \%$ in Laboratory A, $71 \%$ in Laboratory B, $111 \%$ in Laboratory $\mathrm{C}$, and $10 \%$ in Laboratory $\mathrm{D}$. Overall, the ratio of the near-field to far-field peak concentration was $1.51 \pm 0.59[-]$, and the latter typically occurred 
$<1 \mathrm{~min}$ following the near-field peak occurrence. Exposure to elevated particle concentrations occurred mainly for the production period and stopped a few minutes after production ended. Number concentration quickly returned to background levels. Peak concentrations during production and the relative increase in number concentration did not correlate with production time, rate, or nanoparticle yield. During the long production of $\mathrm{Ta}_{2} \mathrm{O}_{5} / \mathrm{SiO}_{2}$ in Laboratory $\mathrm{C}$, airborne particle levels reached steady-state concentrations at $\sim 20000 \mathrm{~cm}^{-3}$ with sharp peaks occurring during the start-up process (see supplementary Figure S3, available at Annals of Occupational Hygiene online).

Concentrations in the breathing zone in Laboratory $\mathrm{A}$ and near-field position in Laboratories B-D were measured in terms of PN1 number $\left(\mathrm{PN}_{\mathrm{NF}}\right)$ and PM1 mass $\left(\mathrm{PM} 1_{\mathrm{NF}}\right)$. In the far field, PN1 number $\left(\mathrm{PN} 1_{\mathrm{FF}}\right)$ and PM10 mass $\left(\mathrm{PM} 10_{\mathrm{FF}}\right)$ concentrations were recorded. On a daily basis and per particle, $85 \%(n=26)$ of the events displayed a weak but statistically significant correlation of $r^{2}=0.27(P<$ $0.01)$ and $r^{2}=0.22(P=0.04)$ for $\mathrm{PN} 1_{\mathrm{NF}}$ and $\mathrm{PM} 1_{\mathrm{NF}}$ and for $\mathrm{PN} 1_{\mathrm{FF}}$ and $\mathrm{PM} 10_{\mathrm{FF}}$, respectively. Mass concentrations $\mathrm{PM} 1_{\mathrm{NF}}$ and $\mathrm{PM} 10_{\mathrm{FF}}$ displayed a better correlation of $r^{2}=0.62(P=0.026)$. Constant mass monitoring of PM10 particle levels also took place. In Fig. 3e, the normalized mass concentration of the constantly monitored PM10 (PM10 ${ }_{\mathrm{CST}}$ ) shows that this monitoring fails to signal higher submicron particle concentrations. No correlations were detected between the PM10 $10_{\mathrm{CST}}$ and the other submicron metrics of number or mass for the investigated days in Laboratory B.

Changes in the production system appeared to have an influence on airborne concentrations in certain cases. In the instances of $\mathrm{Bi}_{2} \mathrm{O}_{3}$ and $\mathrm{BiPO}_{4}$, elevation of the filter-to-flame distance and additionally a change in the strength of the flame by changing the precursor-to-oxygen ratio for the later compound (Madler et al., 2002a) resulted in breathing zone concentrations of over 20 and 30 times the background level, for $\mathrm{Bi}_{2} \mathrm{O}_{3}$ and for $\mathrm{BiPO}_{4}$, respectively, as compared to the average peak-to-background ratio of 1.1 and 1.7 for $\mathrm{Bi}_{2} \mathrm{O}_{3}$ and $\mathrm{BiPO}_{4}$, respectively, under regular production conditions. Another example is the production of a $\mathrm{Pt} / \mathrm{Ba} / \mathrm{Al}_{2} \mathrm{O}_{3}$ catalyst. This was produced by the combination of two flames rather than a single one and resulted in airborne average peak levels of $15000 \mathrm{~cm}^{-3}$ (Supplementary Figure S2, available at Annals of Occupational Hygiene online). During this production, the pattern of airborne particle concentrations was consistent and occurred for all production events $(n=10)$ of the catalyst, in contrast to the production runs with a single flame that resulted in highly variable airborne levels, under the same production rate and with the same operator.
Temperature and relative humidity remained stable at average values of $23.7^{\circ} \mathrm{C}(\mathrm{RSD}=6 \%)$ and $45.4 \%$ $(\mathrm{RSD}=22.5 \%)$, respectively. Average air velocities were $0.041 \mathrm{~m} \mathrm{~s}^{-1}(\mathrm{RSD}=124 \%)$ and $0.053 \mathrm{~m} \mathrm{~s}^{-1}$ $(\mathrm{RSD}=59 \%)$ in the near-field and far-field positions, respectively (for laboratory specific air velocities, see supplementary Figure S4, available at Annals of Occupational Hygiene online). Microenvironmental conditions remained stable throughout the process and hence an effect of these or changes to them on exposure levels could not be established.

\section{Size distribution}

Laboratory A background days were used to obtain background particle size distributions. The average of all background days displayed a log-normal distribution with a peak at $\sim 47 \mathrm{~nm}$ (see supplementary Figure S5, available at Annals of Occupational Hygiene online). Figure 4 displays an example of the size distribution during $\mathrm{BiPO}_{4}$ production in Laboratory A. During this production day, airborne particle concentrations display log-normal distributions with peaks $\sim 160 \mathrm{~nm}$, demonstrating that airborne particles are mainly above the $100 \mathrm{~nm}$ nanoparticle cut-off size. During the decline phases, peaks occur between 169 and $188 \mathrm{~nm}$ for production events 1 and 2, respectively. The number and size distribution results indicate that coagulation, as a removal process, is not important at the monitored positions because the coagulation rate is too slow (Friedlander, 1977). However, coagulation could be a significant removal process in the close proximity of the reactors where number concentrations are expected to be higher.

The different types of produced particles typically exhibited a unimodal log-normal distribution. $\mathrm{BiPO}_{4}$,

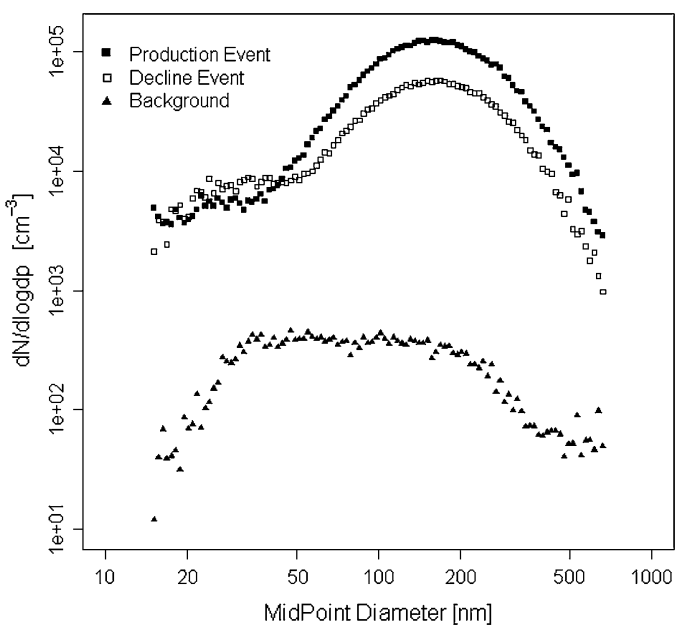

Fig. 4. Size distribution profile during background (filled triangles), production (filled squares), and post-production (open squares) conditions for $\mathrm{BiPO}_{4}$ production in Laboratory A. 
$\mathrm{Bi}_{2} \mathrm{O}_{3}$, and $\mathrm{CaSO}_{4}$ size distributions in Laboratory A peaked at 157,112 , and $169 \mathrm{~nm}$, respectively. This is important considering their differences in hygroscopicity and hence the influence on their growth patterns. The production of $\mathrm{NaCl}$ nanoparticles in Laboratory A was the only compound that resulted in a bimodal size distribution. The expected particle size of the product was between 60 and $80 \mathrm{~nm}$ (Grass and Stark, 2005). Nonetheless, the size distribution during production displayed a small peak at $24-29 \mathrm{~nm}$ and a second peak of greater concentration at $117-130 \mathrm{~nm}$, indicating possible influences of particle properties in the resulting exposure conditions.

Production of nano-gypsum was examined with a hotter flame than above. Typical production conditions lead to particles in the $20-50 \mathrm{~nm}$ size range, as determined by X-ray diffraction (Osterwalder $e t$ al., 2007), while airborne particle concentrations peak at $160-185 \mathrm{~nm}$. The flame temperature was then altered from a low-temperature $3 / 7$ flame to a hot 5/5 flame (Camenzind et al., 2005), resulting in smaller particles. The resulting size distributions of the airborne particles in Laboratory A displayed higher instability. During production with the hotter flame, ambient airborne particle peaks were detected from 55 to $127 \mathrm{~nm}$, leading to an increased nanoparticle size exposure than normal production conditions. The maximum number concentration did not change significantly, as the peak-to-background ratio was $2.41 \pm 0.90[-]$ and changed to $1.87 \pm 0.75[-]$ under the hotter flame. A change in filter-to-flame distance was also investigated. Elevating the distance from 52 to $71 \mathrm{~cm}$ during $\mathrm{BiPO}_{4}$ production resulted in an increase in number concentration by a factor of 30 . However, the size distribution was not affected.

\section{Particle emission rates}

The far-field steady-state concentration of Laboratory C (see supplementary Figure S3, available at Annals of Occupational Hygiene online) was 12 $540 \pm 5840 \mathrm{~cm}^{-3}$. This laboratory has a constant and fixed exchange rate of $10 \mathrm{~h}^{-1}$ (Angst, B.J., ETH Zurich). Inserting these values in equation (1) resulted in an emission rate of $1.2 \times 10^{12} \mathrm{~min}^{-1}$. In Laboratory $\mathrm{D}$, total removal rates were estimated from all production events by fitting exponential curves to the declining number concentrations. In addition to ventilation, also all other loss processes (such as sorption and coagulation) are considered in this removal rate. Over all production events, this resulted in an average effective removal rate of $3.06 \pm 0.98 \mathrm{~h}^{-1}$ for Laboratory D. Air exchange rates due to the mechanical ventilation system varied from 2 to $10 \mathrm{~h}^{-1}$ according to the building management office (Angst, B.J., ETH Zurich). This encompasses the value for the effective removal rate and therefore the range of $2-10 \mathrm{~h}^{-1}$ is used as the lower and upper bound to estimate particle emission rates. The back- ground concentration was used as $C_{0}$ and peak concentrations and time to peak were used for $C$ and $t$. Under an exchange rate of $2 \mathrm{~h}^{-1}$, average estimated emissions from all production events in Laboratory $\mathrm{D}$ were $1.3 \times 10^{11} \pm 0.7 \times 10^{11} \mathrm{~min}^{-1}$ and under a rate of $10 \mathrm{~h}^{-1} 3.8 \times 10^{11} \pm 1.8 \times 10^{11} \mathrm{~min}^{-1}$. Due to the high spatial variations and low production times in the other laboratories, we did not determine emission rates for the Laboratories A and B.

\section{DISCUSSION}

Submicron particle emission, concentration, and exposure can be elevated during nanoparticle production in research laboratories. PN1 particle number concentrations reached levels of up to $106000 \mathrm{~cm}^{-3}$, which is comparable to levels found in carbon black production and carbon nanotube handling (Kuhlbusch et al., 2004; Maynard et al., 2004). PN1 concentrations were higher than the $3180 \mathrm{~cm}^{-3}$ background concentration plus standard deviation in $>40 \%$ of the production events, for both the near field and far field. These results indicate elevated exposure for all researchers present.

While chemical analysis of the ambient particles was not completed, the evidence provided by the onset of particle concentrations increases; the time occurrence of peak concentrations (Fig. 3 and supplementary Figure S2, available at Annals of Occupational Hygiene online) and the steady-state concentrations achieved during the long production in Field C (Supplementary Figure S3, available at Annals of Occupational Hygiene online) confirm that the airborne particle levels are a result of the nanoparticle production process. Exposure times to increased concentrations were associated with production activity and occurred for relatively short time periods.

While the case of laboratories refers to a specialized workplace dealing mainly with small volumes and production times, it is a recognized area of concern in nanoparticle risk assessment (Maynard and Pui, 2007). In a first instance, all new nanoparticles, nanotubes, and nanomaterials are produced in laboratories. For these new compounds with novel properties almost no toxicological data may exist, and, as in the present study, the lack of threshold-limit values may not permit a hazard or risk classification of exposure levels. Additionally, while the small scale may be the norm, it is shown here that large batch productions leading to extended periods of exposure can be a reality. Scientific and technological requirements are pushing to greater production volumes even in research laboratories (Athanassiou et al., 2006). FSP is currently able to produce over $1 \mathrm{~kg} \mathrm{~h}^{-1}$ of nanoparticles (Mueller et al., 2003). This may lead to greater exposures and risks. In this context, studies trying to quantify and characterize exposure, as done 
in the current paper, are extremely important to minimize the hazards and risks of potential adverse health effects.

Conducting measurements in real-life settings, while highly valuable, adds constraints to the monitoring process. For instance, for operational reasons, the closest position that could be monitored was $0.5 \mathrm{~m}$ away from the researcher's standing position. Our position for the breathing zone concentration (P1) was therefore $\sim 1.5 \mathrm{~m}$ away from the source. Therefore, the spatial variability observed may be more significant at the zone closer to the source. Taking lessons from chemical monitoring, it is a necessity that the nanotechnology field advances further in the creation of advanced monitoring tools that will enable personal monitoring in workplaces.

Occupational safety measures were in place in these laboratories. These included all researchers wearing protective masks and clothing, producing known toxic substances in an enclosed reactor (Athanassiou et al., 2006), situating and operating the reactor system in fume-hoods, and allowing three air exchanges after production ends before opening the fume-hood. Furthermore, airborne PM10 concentrations are constantly monitored in these laboratories and continuous indication labelling outside the laboratory was placed forewarning of ongoing production of nanoparticles that required all persons entering to wear protective masks. Despite the safety measures in place, it is demonstrated that an elevated airborne submicron particle level can occur. Therefore, questions remain as to the effectiveness of the applied safeguards and required technological changes to further protect researchers' health. For instance, in the described production settings, the operator is required to open the fume-hood for flame ignition and cessation. Additionally, if problems in the production occur, opening of the fume-hood is necessary. Therefore, the source of the exposure problem is identified as the use of nonfully enclosed fume-hoods and non-automation of the process at this stage. Future directions in the build-up of these reactor systems thus include their optimization and complete automation, which would circumvent any necessity of researchers having to deal directly with open-flame reactions. Steps in this direction are being made in the studied laboratories for complete enclosure of flame reactors. Further safety measures would see the installation of stopwatches on-site or lock systems on automated systems that would seal the enclosure until the concentration in the system reached appropriate levels. Such examples are often seen in technological advances in protective measures against chemical exposure, as for instance, in metal degreasing (Von Grote et al., 2003).

A key operational question remains of the appropriateness of a metric to characterize nanoparticle exposure. It is observed that the current monitoring measures of the PM10 mass-based particle fraction alone, while ensuring occupational regulatory values are met, cannot be used as a signalling measure of high submicron and nanoparticle levels. This could be of great consequence especially in the event of accidents. While Wilson (2006) reports that the risk associated with most of the nanomaterial production processes is comparable or lower than common non-nanoprocesses (Wilson, 2006), the event of accidents must be considered (Sequeira et al., 2006). In the cases investigated here, it is demonstrated that measured peak particle concentrations are in the low size ranges, $<200 \mathrm{~nm}$ and even in the nanoparticle range, depending on production conditions. Because mass concentrations are dominated by larger particles, they may not capture the release of potentially high and hazardous concentrations in the case of accidents. Thus, the installation of submicron number particle counters for continuous monitoring would be an enhanced safety and warning mechanism. One should recognize, however, that high number concentrations in the case of accidents would rapidly drop by coagulation leading to micron-sized aggregates or agglomerates (Friedlander, 1977).

Results on exposure levels during nanoparticle synthesis are particularly important at early stages in the field of nanotechnology and its risk assessment. Warheit et al. (2007) advocate that a number of parameters are required to establish safety measures for nanomaterials. The American National Standards Institute recommends the build-up and development of a protocol for exposure metrics and data standard requirements (Morgan, 2005). A framework as such would describe the monitoring needs and the methodological framework to follow, leading to increased transparency and comparativeness of results across studies.

\section{SUPPLEMENTARY DATA}

Supplementary data, Tables S1 and S2 and Figures S1-S5 can be found in the online edition.

Acknowledgements-The authors are grateful to Professor Sotiris E. Pratsinis (Director of the Particle Technology Laboratory at ETH Zurich) for his valuable input and feedback to an earlier version of this manuscript, for useful discussions and for allowing measurements in his laboratories and providing the CPC3022A and SidePak ${ }^{\mathrm{TM}}$ (model AM510) for the measurements. The authors also wish to thank all the members of the Particle Technology (PTL) and Functional Materials Laboratories (FML) at ETH Zurich for their assistance during this project and especially Heiko Schultz (currently at BASF AG, Ludwigshafen, Germany), Reto Strobel (PTL), and Samuel Halim (FML) for their assistance during the experiments.

\section{REFERENCES}

Aitken RJ, Creely KS, Tran CL. (2004) Nanoparticles: An Occupational Hygiene Review. Research Report 274. H. a. S. Executive. Edinburgh, UK: Institute of Occupational Medicine (IOM). 
Athanassiou EK, Grass RN, Stark WJ. (2006) Large-scale production of carbon-coated copper nanoparticles for sensor applications. Nanotechnology; 17: 1668-73.

Brunner TJ, Wick P, Manser P et al. (2006) In vitro cytotoxicity of oxide nanoparticles: comparison to asbestos, silica, and the effect of particle solubility. Environ Sci Technol; 40: 4374-81.

Camenzind A, Strobel R, Pratsinis SE. (2005) Cubic or monoclinic Y2O3: Eu3 + nanoparticles by one step flame spray pyrolysis. Chem Phys Lett; 416: 193-7.

Demou E, Peter P, Hellweg S. (2008) Exposure to manufactured nanostructured particles in an industrial pilot. Ann Occup Hyg; 52: 695-706.

Friedlander SK. (1977) Smoke, Dust and Haze. Fundamentals of Aerosol Behavior. New York: John Wiley \& Sons, Inc.

Grahame TJ, Schlesinger RB. (2007) Health effects of airborne particulate matter: do we know enough to consider regulating specific particle types or sources? Inhal Toxicol; 19: 457-81.

Grass RN, Stark WJ. (2005) Flame synthesis of calcium-, strontium-, barium fluoride nanoparticles and sodium chloride. Chem Commun; 1767-9.

He C, Morawska L, Taplin L. (2007) Particle emission characteristics of office printers. Environ Sci Technol; 41: 6039-45.

Heine MC, Pratsinis SE. (2005) Droplet and particle dynamics during flame spray synthesis of nanoparticles. Ind Eng Chem Res; 44: 6222-32.

Jenkins RA, Ilgner RH, Tomkins BA et al. (2004) Development and application of protocols for the determination of response of real-time particle monitors to common indoor aerosols. J Air Waste Manage Assoc; 54: 229-41.

Kandlikar M, Ramachandran G, Maynard A et al. (2007) Health risk assessment for nanoparticles: a case for using expert judgment. J Nanopart Res; 9: 137-56.

Kuhlbusch TAJ, Neumann S, Fissan H. (2004) Number size distribution, mass concentration, and particle composition of PM1, PM2.5, and PM10 in bag filling areas of carbon black production. J Occup Environ Hyg; 1: 660-71.

Limbach LK, Wick P, Manser P et al. (2007) Exposure of engineered nanoparticles to human lung epithelial cells: influence of chemical composition and catalytic activity on oxidative stress. Environ Sci Technol; 41: 4158-63.

Loher S, Stark WJ, Maciejewski M et al. (2005) Fluoro-apatite and calcium phosphate nanoparticles by flame synthesis. Chem Mater; 17: 36-42.

Madler L, Kammler HK, Mueller R et al. (2002a) Controlled synthesis of nanostructured particles by flame spray pyrolysis. J Aerosol Sci; 33: 369-89.

Mädler L, Pratsinis SE. (2002) Bismuth oxide nanoparticles by flame spray pyrolysis. J Am Ceram Soc; 85: 1713-8.

Madler L, Stark WJ, Pratsinis SE. (2002b) Flame-made ceria nanoparticles. J Mater Res; 17: 1356-62.
Maynard A, Baron P, Foley M et al. (2004) Exposure to carbon nanotube material: aerosol release during the handling of unrefined single-walled carbon nanotube material. J Toxicol Environ Health A; 67: 87-107.

Maynard AD, Pui DYH. (2007) Nanotechnology and occupational health: new technologies-new challenges. J Nanopart Res; 9: 1-3.

Morgan K. (2005) Development of a preliminary framework for informing the risk analysis and risk management of nanoparticles. Risk Anal; 25: 1621-35.

Mueller R, Mädler L, Pratsinis SE. (2003) Nanoparticle synthesis at high production rates by flame spray pyrolysis. Chem Eng Sci; 58: 1969-76.

Osterwalder N, Capello C, Hungerbuhler K et al. (2006) Energy consumption during nanoparticle production: how economic is dry synthesis? J Nanopart Res; 8: 1-9.

Osterwalder N, Loher S, Grass RN et al. (2007) Preparation of nano-gypsum from anhydrite nanoparticles: strongly increased Vickers hardness and formation of calcium sulfate nano-needles. J Nanopart Res; 9: 275-81.

Papageorgiou I, Brown C, Schins R et al. (2007) The effect of nano- and micron-sized particles of cobalt-chromium alloy on human fibroblasts in vitro. Biomaterials; 28: 2946-58.

Sequeira R, Genaidy A, Shell R et al. (2006) The nano enterprise: a survey of health and safety concerns, considerations, and proposed improvement strategies to reduce potential adverse effects. Hum Factors Ergon Manuf; 16: 343-68.

Stark WJ, Pratsinis SE. (2002) Aerosol flame reactors for manufacture of nanoparticles. Powder Technol; 126: 103-8.

Strobel R, Madler L, Piacentini M et al. (2006) Two-nozzle flame synthesis of $\mathrm{Pt} / \mathrm{Ba} / \mathrm{Al}_{2} \mathrm{O}_{3}$ for $\mathrm{NO}_{\mathrm{x}}$ storage. Chem Mater; 18: 2532-7.

Strobel R, Pratsinis SE. (2007) Flame aerosol synthesis of smart nanostructured materials. J Mater Chem; 17: 4743-56.

ten Berge WF, Fehrenbacher MC, Jayjock MA et al. (2000) Mathematical Models for Estimating Occupational Exposure to Chemicals. Fairfax, VA: AIHA Press.

Thorpe A. (2007) Assessment of personal direct-reading dust monitors for the measurement of airborne inhalable dust. Ann Occup Hyg; 51: 97-112.

Von Grote J, Hurlimann C, Scheringer M et al. (2003) Reduction of occupational exposure to perchloroethylene and trichloroethylene in metal degreasing over the last 30 years: influences of technology innovation and legislation. J Expo Anal Environ Epidemiol; 13: 325-40.

Warheit DB, Borm PJA, Hennes C et al. (2007) Testing strategies to establish the safety of nanomaterials: conclusions of an ECETOC workshop. Inhal Toxicol; 19: 631-43.

Wilson RF. (2006) Nanotechnology: the challenge of regulating known unknowns. J Law Med Ethics; 34: 704-13. 